\title{
DEBATES
}

\author{
Feminismo para os 99\%: Um manifesto \\ de Cinzia Arruzza, Tithi Bhattacharya e Nancy Fraser. \\ Tradução de Heci Celina Pinto (São Paulo: Boitempo, 2019)*
}

\section{Excessos funcionalistas, feminismos e inimigos mortais**}

\author{
Ana Claudia Lopes \\ lopesanaclau@gmail.com \\ (Universidade de São Paulo, São Paulo, Brasil)
}

Lançado em 8 de março de 2019, Feminismo para os 99\% toma como ponto de partida os diferentes movimentos grevistas de mulheres organizados, a partir de 2016, em mais de 50 países. Para Arruzza, Bhattacharya e Fraser "o feminismo das grevistas antecipa a possibilidade de uma nova fase e sem precedentes da luta de classes: feminista, internacionalista, ambientalista, e antirracista" (p. 34, grifo meu). Partindo desse prenúncio, com 11 teses e um posfácio, as autoras procuram conjugar as linhas basilares de um feminismo que possa "ser fonte de esperança para a humanidade" (p. 42), enquanto convocam "todos os movimentos radicais a se unirem numa insurgência anticapitalista comum" (Tese 11, p. 93) orientada por uma perspectiva "ao mesmo tempo feminista, antirracista e anticapitalista" (p. 96).

\footnotetext{
* As páginas indicadas entre parênteses no corpo do texto referem-se a esta edição.

** Este texto é uma versão ligeiramente modificada do preparado para o debate com Yara Frateschi e Jéssica Valmorbida, na USP, em 21 de novembro de 2019. Agradeço por, apesar das divergências, mantermos um espaço aberto e frutífero de debate e aprendizado conjunto. Agradeço ainda a Ricardo Terra, Adriana Matos, Beatriz Chaves, Lutti Mira, Fernando Del Lama, Sidélia Silva, Júlia Abdalla, Gustavo Rossi e Raíssa Wihby, assim como às pareceristas anônimas ou anônimos, pelas sugestões e importantes questões - muitas das quais, dado o espaço, não pude incorporar ou endereçar.

1 Assinados por outras autoras, os primeiros ímpetos do Manifesto foram, primeiro, logo após a eleição de D. Trump (Alcoff et al., 2017), convocando para um feminismo de base e anticapitalista, e, no ano seguinte, assumindo um discurso mais marcado pela interseccionalidade (Alcoff et al., 2018).
} 
Uma das principais contribuições que perpassa o texto é indicar ter como ponto de partida a intersecção de classe, gênero e raça, dentre outros marcadores, não só como categorias que organizam a vida social, mas também a serem enfrentadas como sistemas de opressão interconectados. Esse tipo de abordagem vem sendo teorizado pelo menos desde os 1970, e não só nos Estados Unidos (onde todas as autoras estão hoje baseadas); mas, ao destacar o desafio à "oposição obstinada e dissociadora entre "política identitária e política de classe”" (p. 34) que seria colocada pela nova onda feminista, o Manifesto faz um aporte importante para uma parcela dos debates políticos contemporâneos. 0 texto também tematiza uma discussão sobre a reprodução social, um tipo de trabalho relacionado ao que chamam de "produção de pessoas", que, embora fundamental, é historicamente (e ainda hoje) invisibilizado e "estruturalmente ligado à assimetria de gênero" (p. 105) - e de classe, de raça, e, em alguns contextos, de nacionalidade. Essa discussão, que acompanha a obra de Fraser desde os anos 1990 e é tema também dos trabalhos de Bhattacharya, foi também feita em diferentes partes do mundo desde os anos 1970, ganhando na década seguinte a rubrica da divisão sexual do trabalho (cf. Hirata \& Kergoat, 2007).

No que se segue, eu gostaria de esboçar alguns questionamentos ao Manifesto. Exceto por um diálogo subterrâneo, e, talvez por isso, fundamental, com Frateschi (2019), não vou discutir sua recepção no Brasil. Esse enfoque chega a ser um pouco injusto, pois a forma manifesto, a despeito de suas limitações, pretende-se imbricada com alguma convocação para a ação política, e o Manifesto ressoou particularmente na ação não só de duas deputadas federais da estatura de Joenia Wapichana (REDERR) e Talíria Petrone (PSOL-RJ) - como mostram suas contribuições para a orelha e o prefácio da tradução, respectivamente -, como, do mesmo modo, vem tendo suas ressonâncias para outras organizações e teóricas feministas. Além disso, não vou reduzir o Manifesto a um panfleto desprovido de qualquer pretensão ou base teórica. Entendo que o texto pretende ser acessível a um público mais amplo e menos especializado do que aqueles com os quais os trabalhos de suas autoras poderiam confortavelmente se conformar, mas, por isso mesmo, que não pode ser tratado como desprovido de um conjunto significativo de pressupostos teóricos e implicações políticas. Para discussão, gostaria de levantar questões relacionadas aos seguintes pontos: Primeiro, a conceitualização abrangente de capitalismo; segundo, a caracterização e identificação entre feminismo liberal, feminismo corporativo e feminismo do 1\%; por fim, a política que, já longe daquela do melhor argumento, abandona até mesmo os adversários e opta por caracterizar um inimigo.

\section{Um capitalismo faz-tudo}

$\mathrm{Na}$ letra do Manifesto, o capitalismo é entendido como "uma ordem social institucionalizada" (p. 102) que diz respeito a relações e práticas as quais, em sua aparência, não são manifestamente econômicas, mas que são, por outro lado, 
fundamentais para a economia oficial. Enquanto única e mesma ordem ou sistema social, o capitalismo é apresentado como a fonte única não só da exploração do trabalho (assalariado e não assalariado), mas também das opressões baseadas em gênero, raça, etnia, dentre outras. Esse sistema, afirma-se, também foi responsável pelo colonialismo, além de ser responsável pelo atual imperialismo e pelos desastres ambientais. Como as autoras escrevem: "as várias opressões que sofremos não formam uma pluralidade incipiente e contingente. Embora cada uma tenha as próprias formas e características, todas estão enraizadas em um único e mesmo sistema social e são por ele reforçadas" (p. 95, grifo meu).

Essa compreensão ampliada do capitalismo ecoa os trabalhos mais recentes de Fraser (p. ex. Fraser, 2014), quem, procurando revisitar e distinguir uma nova teoria do capitalismo, e, em particular, das crises do capitalismo, tem o mérito de procurar elaborar um diagnóstico "abrangente" - como a autora, já desde os anos 1980, argumenta ser tarefa da crítica (Fraser \& Nicholson, 1989). Depois da acertada recusa da totalidade (Jay, 1984), Fraser, também acertadamente, recusa que o nominalismo de narrativas locais e fragmentadas seja a única possibilidade para o diagnóstico. Apesar desse mérito, na maneira como aparece no Manifesto, o diagnóstico do capitalismo corre o risco de ser excessivamente funcionalista e potencialmente indiferenciado.

Em vista dos desastres ambientais, dada a forma predatória que, a despeito de suas reconfigurações, o modo de produção e reprodução capitalista não abandonou ao longo dos últimos 200 anos, e em vista da pobreza e da extrema pobreza, não chego a ter dificuldades em compreender a caracterização. Sobre o colonialismo, que, embora o livro não mencione, deu-se de maneiras muito diferentes e em momentos diferentes em diferentes partes do mundo, o imbricamento também é plausível. Ainda assim, tenho dúvidas sobre o quanto, atualmente, discursos anticolonialistas e anti-imperialistas não caem como luvas para que elites políticas e econômicas locais se desresponsabilizem pelas expropriações que promovem sobre a riqueza de seus Estados e pela subjugação a que impõem seus concidadãos. ${ }^{2}$ Minha principal dificuldade, porém, é como e por que, apesar de ressalvas como a de que "o capitalismo (...) não inventou a subordinação das mulheres" (p. 51), racismo, etnonacionalismo e sexismo são não só condições sistêmicas do capitalismo, mas, na história recente, só e apenas do capitalismo.

Em resumo, o capitalismo acaba sendo caracterizado como um único e mesmo sistema social, e, ademais, como multifacetado e onipotente, pois fonte única das principais opressões de nosso tempo. O Manifesto, além disso, sugere como aposta implícita que, uma vez abolido o sistema social capitalista, passaríamos a ser não racistas e não sexistas.

2 Cf. Phimister \& Raftopoulos (2004), que analisam os usos do discurso anti-imperialista por Robert Mugabe, e Pacciardi et al. (2019), que também recuperam esses usos por líderes populistas antiliberais. 


\section{Feminismo liberal, feminismo corporativo?}

Meu segundo conjunto de questões concerne à oposição entre duas - e apenas duas - concepções de feminismo que organiza o livro. De um lado, temos o feminismo que as autoras pretendem construir para os $99 \%$. Do outro lado, temos o que se chama ora de feminismo corporativo, ora de feminismo liberal, ora de feminismo do $1 \%$. Esse feminismo, que seria propagado pela variante supostamente progressista do neoliberalismo, aparece já nas primeiras linhas da introdução, e a expressão escolhida para o subtítulo dessa seção é significativa: vertida para o português como "Uma encruzilhada", "A fork in the road" conota uma situação difícil em que há uma escolha definitiva e sem volta entre apenas dois caminhos. Conforme as teses são apresentadas, a oposição, estanque, fica ainda mais clara, pois o feminismo corporativo, do 1\%, liberal, é apresentado como um dos "principais obstáculos" (p. 119), como um dos inimigos mortais do "feminismo genuinamente emancipatório e majoritário" (p. 100) - o outro inimigo mortal é o populismo reacionário, que, contudo, é entendido como resultante do neoliberalismo progressista (idem). Vou abordar a questão do inimigo adiante, mas, antes, gostaria de interrogar a identificação do feminismo antagônico.

Esse feminismo é primeiramente encarnado pelas autoras na figura de uma mulher, Sheryl Sandberg. E, depois, em Hillary Clinton, na esteira de sua candidatura às eleições presidenciais nos EUAem 2018, ou em outras referidas como "Sandberg e sua laia" (p. 26), como "femocratas [femocrats]" (pp. 39, 61), "3 "neoliberais progressistas de saias" (p. 61), "belicistas de saias" (p. 91). Essa estratégia (meramente figurativa?) de encarnar em indivíduos específicos certos ideais ou, em outro sentido, personificar esses ideais em imagens claramente desdenhosas seria por si só problemática. Eu perguntaria por que, com a pretensão de ser popular, consideram a vituperação um tom adequado. E perguntaria, ademais, qual ideal de mulher subjaz a essas categorias acusatórias, de modo que, num manifesto alegadamente interseccional, faz sentido recorrer à metáfora das "saias" para questionar o caráter de ser mulher de um "ser belicista" que, embora use saias, talvez - fica sugerido - não seja "mulher".

De todo modo, Sheryl Sandberg ganhou fama a partir do início da década passada por ser alta executiva do Facebook, e, a partir de seu primeiro livro, traduzido no Brasil como Faça acontecer, por ter passado a promover um feminismo, que, nas palavras de apresentação da fundação que leva o mesmo nome, coloca como missão "ajudar as mulheres a conquistar suas ambições e trabalhar para criar um mundo igual". ${ }^{4} \mathrm{O}$ argumento central daquele livro - que "até é uma espécie de manifesto feminista" (Sandberg, 2013) - é o de que as empresas e instituições governamentais devem melhorar as condições de trabalho e acesso a posições de liderança para as

3 A tradução brasileira mitiga o tom do neologismo ao traduzir como "burocratas do sexo feminino" e como "feministas burocratas".

4 Cf. a página: https://leanin.org/about (Acesso em: 28 abr. 2020). 
mulheres, mas que, sobretudo, são as mulheres que têm de "fazer acontecer" e, para isso, precisam superar as "barreiras internas" impingidas pela socialização. Sandberg traça o caminho: "aumentar nossa autoconfiança (...), fazer nossos parceiros ajudarem mais em casa, (...), não nos prender a modelos inatingíveis” (idem). Esse feminismo, a bem dizer, tem muitos aspectos bastante controversos e criticáveis, não apenas os que rondam a atuação e os interesses de Sandberg, mas também, como já foi apontado (p. ex. Aschoff, 2015; Bruenig, 2015), por se tratar de um feminismo restrito a mulheres (cis-heterossexuais) com um determinado status social que, "fazendo a acontecer”, podem piorar ainda mais as condições de vida e trabalho não só de outras mulheres, mas de todos os outros. Trata-se de um feminismo individualista, que presume que a escolha de se impor ou não é estritamente individual $e$ livre, e que, nas palavras acertadas do Manifesto: "se recusa firmemente a endereçar as restrições socioeconômicas que tornam a liberdade e o empoderamento impossíveis para uma ampla maioria de mulheres” (p. 37). Mas é essa uma boa caracterização dos feminismos liberais?

Se tomamos o individualismo, encontramos a premissa do individualismo ético, por exemplo, em uma expoente feminista liberal como Martha Nussbaum (1999, p. 59-67). Mas o individualismo ético, aqui, não está relacionado ao egoísmo nem depende do individualismo ontológico, isto é, não se trata de articular os desejos e as escolhas individuais apenas em vista do interesse ou benefício próprios nem de tomar a sociedade como constituída por indivíduos isolados e a despeito de seus vínculos e condições sociais constitutivos. Antes, o individualismo ético está relacionado a um princípio, herdado da filosofia kantiana, segundo o qual cada indivíduo deve ser considerado como fim em si (e não como meio). O ideal da livre escolha (por algumas feministas liberais chamado de autonomia pessoal) também está vinculado ao individualismo ético (idem, p. 5; cf. também Assumpção, 2018, p. 81). Ambos, porém, se são fundamentais, não são as únicas premissas dos feminismos liberais, nos quais as preocupações com as liberdades não estão separadas das da igualdade econômica e política. O próprio enfoque das capacidades (capabilities) de Nussbaum, por exemplo, não prescinde de um desenvolvimento mais amplo do indivíduo, um "florescimento" (tradução de eudaimonia que por anos vigorou nos estudos aristotélicos de língua inglesa), que não pode ser separado do da comunidade e de condições materiais (Nussbaum, 1999, p. 50; cf. também Borges, 2018; Ali \& Piroli, 2019).

É verdade que autores entendidos como parte da tradição liberal podem ser lidos como pressupondo um conjunto de princípios como se fossem dados no presente - e, sabemos, liberdade e igualdade estão longe de serem efetividade. Mas o liberalismo contemporâneo, em grande parte, já se desfez dessas ilusões. É verdade também que, no mais das vezes, as teorias liberais parecem prescindir da ação política coletiva e de espaços públicos vibrantes (cf. p. ex. Benhabib, 1992, p. 94-104; Habermas, 1995). E, no entanto, existe uma diferença crucial em, de um lado, 
apontar a parcialidade e as limitações de uma posição, e, de outro, destacar, quando não distorcer, apenas as posições e pressupostos problemáticos. Considero, portanto, a estratégia de identificar a tradição do feminismo liberal com o feminismo do "faça acontecer", ou, nesse caso, corporativo, do $1 \%$, infrutífera e contraproducente. Por um lado, mesmo esse feminismo corporativo pode acabar sendo uma porta de entrada para os diferentes debates feministas, antirracistas e igualitários - e acrescentaria que, em um país como o Brasil, onde parte do discurso público demoniza, quando não queima (Cyfer, 2018), qualquer manifestação de feminismo, esse feminismo parece ser mais aliado do que oponente. Por outro lado, se é possível criticar os feminismos liberais e a tradição liberal, como mostram também as muitas disputas dentro dessas mesmas tradições, não me parece que, no caminho para transformações radicais (que, e nesse ponto estou de acordo, erramos se as excluímos de nosso horizonte emancipatório), devamos abandonar as orientações normativas da justiça da estrutura básica que busca liberdades básicas e a maior igualdade possível.

Não custa lembrar que liberalismo e neoliberalismo econômicos não são o mesmo que liberalismo igualitário e/ou político. De todo modo, a identificação entre feminismo corporativo, do 1\%, e feminismo liberal, tem também por consequência o esvaziamento político e teórico não apenas dos feminismos liberais, mas de quaisquer outros feminismos que não o do Manifesto. Por reduzir a apenas duas opções os diferentes feminismos e movimentos de mulheres e por se alçar como a única síntese possível de tudo aquilo que merece o nome de "genuinamente" feminista, o feminismo do Manifesto acaba substituindo a aliança pela síntese potencialmente violenta. Mas em nome de quem?

\section{0 mundo dividido em dois}

O feminismo autodeclarado para os $99 \%$ tem mais do que posições e pressupostos com os quais diverge, e mais até do que um oponente ou um adversário. Esse feminismo tem, uma vez mais, "inimigas mortais" (p. 100). As dificuldades com o tipo de construção política que se aproxima ou ressoa àquela que, para emprestar palavras de Arendt (1989, p. 417), "afirma ser o mundo dividido em dois gigantescos campos inimigos, um dos quais é o movimento, e que este [o movimento] pode e deve lutar contra o resto do mundo" não deveriam ser ignoradas. É verdade que o feminismo para os $99 \%$ afirma ser somente o seu campo o campo gigantesco, diante do diminuto $1 \%$, que, entendido como o $1 \%$ que concentra renda e riqueza, também considero indefensável (do ponto de vista do argumento liberal e igualitário, aliás). Não obstante, e é por isso que apontei algumas questões sobre o diagnóstico do capitalismo no início, a conceitualização de capitalismo como sistema social que tudo abrange e tudo causa pouco nos ajuda a compreender o funcionamento (e as crises) dos sistemas econômicos, políticos, sociais em sua interligação e desdobramentos globais e, por que não, locais. Se, do ponto de vista do diagnóstico, parece sobrar 
pouco espaço para uma reflexão, igualmente abrangente, mas mais complexificada (mais histórica e empiricamente informada), do ponto de vista normativo, com a política do inimigo, e do unificado inimigo, na base, parece sobrar pouco espaço para divergências internas e externas, e, talvez, para a política.

Sem dúvida, podemos estar diante de estratégias retóricas - hipérbole, slogan, ou algum outro traço característico de um manifesto. Pode ser o caso, e isso nos exigiria considerar as limitações da forma. Apesar disso, é preciso não esquecer como, historicamente, caracterizações “do inimigo” levaram e levam ao confinamento e à aniquilação real de pessoas. E é preciso não esquecer que essas caracterizações sempre puderam ser alargadas para que coubessem mais do que inicialmente se supunha - inclusive em nome do que as autoras chegam a chamar de "lapsos [sic] políticos e intelectuais" (p. 121) de "seguidoras e seguidores de Marx" (idem). Em uma sociedade que deu mais de 57 milhões de votos a um presidente como o atual, talvez já fosse tempo de termos aprendido a caracterizar "a luta" com um pouco mais de espaço para a divergência e para a pluralidade: mais orientada para o embate do convencimento, do que para o das palavras de ordem. Estas, no melhor dos casos, limitam nossa capacidade de compreensão. No pior, com ou sem "lapsos", nutrem ressentimentos e divisões estanques e, historicamente, fomentam os piores e mais reacionários efeitos.

\section{Referências}

Alcoff, L. M., Arruzza, C., Bhattacharya, T., Clemente, R., Davis, A., Eisenstein, Z., Featherstone, L., Fraser, N., Smith, B., \& Taylor, K.-Y. (2018, 27 jan.). We need a feminism for the $99 \%$. That's why women will strike this year. The Guardian. Recuperado de: https://www.theguardian.com/commentisfree/2018/jan/27/ we-need-a-feminism-for-the-99-thats-why-women-will-strike-this-year. Acesso em: 28 abr. 2020.

Alcoff, L. M., Arruzza, C., Bhattacharya, T., Fraser, N., Ransby, B., Taylor, K.-Y., Odeh, R. Y., \& Davis, A. (2017, 6 fev.). Women of America: We're going on strike. Join us so Trump will see our power. The Guardian. Recuperado de: https: //www. theguardian.com/commentisfree/2017/feb/06/women-strike-trump-resistancepower. Acesso em 28 abr. 2020.

Ali, N. , \& Piroli, D. (2019). Teoria parcial de justiça e estrutura política democrática na teoria de Nussbaum. ethic@, 18(3), pp. 333-356. Doi: 10.5007/1677-2954.2019v1 $8 \mathrm{n} 3 \mathrm{p} 333$.

Arendt, H. (1989). Origens do totalitarismo. Tradução de R. Raposo. São Paulo: Companhia das Letras.

Aschoff, N. (2015). "Sheryl Sandberg and the business of feminism". In: The new prophets of capital. London: Verso.

Assumpção, S. R. (2018). Ambiguidades do liberalismo político feminista: Reflexões sobre Martha Nussbaum à luz de questões latino-americanas. Cadernos Adenauer, 19, pp. 75-91.

Benhabib, S. (1992). Situating the self: Gender, community, and postmodernism in contemporary ethics. Nova York: Routledge. 
Borges, M. (2018). O feminismo universalista de Martha Nussbaum.ethic@, 17(2), pp. 205-216. Doi: 10.5007/1677-2954.2018v17n2p205.

Bruenig, E. (2015, 9 mar.). Sheryl Sandberg's lean in philosophy doesn't just ignore disadvantaged women. It hurts their cause. The New Republic. Recuperado de: https://newrepublic.com/article/121249/sheryl-sandbergs-lean-feminism-putswomen-issues-risk. Acesso em: 28 abr. 2020.

Cyfer, I. (2018). A bruxa está solta: Os protestos contra a visita de Judith Butler ao Brasil à luz de sua reflexão sobre ética, política e vulnerabilidade. Cadernos Pagu, 53. Doi: 10.1590/18094449201800530003.

Fraser, N. (2014). Behind Marx's hidden abode: For an expanded conception of capitalism. New Left Review, 86, pp. 55-72.

Fraser, N., \& Nicholson, L. (1989). Social criticism without philosophy: An encounter between feminism and postmodernism. Social Text, 21, pp. 83-104. Doi: $10.2307 / 827810$.

Frateschi, Y. (2019, 18 out.). Resenha de: Fraser, Nancy; Aruzza, Cinzia; Bhattacharya, Tithi. Feminismo para os 99\%. Um manifesto. São Paulo: Boitempo, 2019. Boletim Lua Nova. Recuperado de: https://boletimluanova.org/2019/10/18/resenhade-fraser-nancy-aruzza-cinzia-bhattacharya-tithi-feminismo-para-os-99-ummanifesto-sao-paulo-boitempo-2019. Acesso em: 28 abr. 2020.

Habermas, J. (1995). Três modelos normativos de democracia. Tradução de G. Cohn e A. de Vita. Lua Nova, 36, pp. 39-53. Doi: 10.1590/S0102-64451995000200003.

Hirata, H., \& Kergoat, D. (2007). Novas configurações da divisão sexual do trabalho. Cadernos de Pesquisa, 37(132), pp. 595-609. Doi: 10.1590/S010015742007000300005.

Jay, M. (1984). Marxism and totality: The adventures of a concept from Lukács to Habermas. Berkeley: University of California Press.

Nussbaum, M. C. (1999). Sex \& social justice. Nova York: Oxford U P.

Pacciardi, A., Söderbaum, F., \& Spandler, K. (2019). Contestations of the liberal international order: A populist script of regional cooperation. In: GGS Annual Conference, Giessen, Alemanha. Recuperado de: https: //www.researchgate. net/publication/337772345. Acesso em: 28 abr. 2020.

Phimister, I., \& Raftopoulos, B. (2004). Mugabe, Mbeki \& the politics of antiimperialism. Review of African Political Economy, 31(101), pp. 385-400. Doi: 10.1080/0305624042000295503.

Sandberg, S. (2013). Faça acontecer. Tradução de D. Bottmann. São Paulo: Companhia das Letras. 